ointment was applied until the discharge stopped, which took place in about cleven hours.

The mixture was changed for the compound decoction of aloes, and the pills were ordered to be taken occasionally, as her mouth was rather sore. From this time the character of the sores changed. They assumed a bettcr appearance, and healthy granulations appeared on the surface. Towards the next month a slight discharge came from the vagina, and none from the ulcers, and the normal process has continued ever since. Her breasts gradually enlarged, her voice lost its harshness, and the sores nearly healed. Her appetite became good, and, by taking gentle exercise, and using a nourishing diet, she has continued steadily to improve in health to this time. She has now returned to the country to her usual employment.

Blyth, Northumberland, January, 1834.

\section{CHLORIDI OF GOLD AND SODA IN SYPHILIS.}

\section{To the Editor of THis LaxceT.}

Sin,-It may be remembered by yourself, although decidedly not by the rest of the profession, that I ventured to recommend to their adoption the exhibition of chloride of gold and soda, for the cure of all the forms of syphilis, on the evidence of the papers of Drs. Chiestien and Benaben, detailing three casss, which appeared in your useful publication,-confirmed in my belief by four other instances gccurring in my practice (one of which involved two varieties, recent chancre and secondary symptoms), in all of which that salt produced the most beneficial effects, $v$ ithout any external indication for its employment, except a blueness onthe skin of the tongue, as if it had been dyed from sucking a pen after having written with ink, and which soon after disappeared.

This communication was made to THE LANCET on the 10th of July, 1830 (Nio. 358), and ever since that period I have treated all the forms of this scourge to humanity which presented themselves, in the manner thore advised, and with the most complete success.

I have a list of forty cases which were thus cured within less than two years subsecuent to the above date, many of which I have been enabled to watch to the present moment, and in none of these have secondary symptioms supervened. Sincel that period I have not preserved a register of cases, but very numerous would have been the entries if I had done so, and the omission I now much regret.*

I am, Sir, yours ever,

R. Dewey Forster, M.R.C.S. 55, Park-street, Grosvenor-square, 7th February, 1834.

\section{STRICTURE OF THE RECTUM.}

\section{CASE OF " CIRCUiAR STRICTURE."}

\section{To the Editor of The LANCET.}

, $\mathrm{In},-\mathrm{I}$ have read, in the pages of your Journal, a part of the controversy between Mr. Salmon and Dr. O'Beirne, wherein the latter gentleman unequivocally denies the existence of circular stricture of the rectum within reach of the finger. As the subject is highly interesting, and most important to medical men, I am induced to trouble you with the particulars of a case at the present time under my care, corrcspouding precisely with the views entertained by Mr. Salmon; and as it bears upon the point ir dispute, you will perhaps give it insertion in your Journal. First, let me refer to a passage in Dr. O'Beirne's letter, in jour publication of the 1st of February, wherein he writes" A surgeon, upon exaniring the rectum per anum, feels that the pouch of the intestine is so open, that he can roll his finger freely about in it; and that on pushing his finger higher up in the direc. tion of the bowel, its point enters a nar. row opening or ring. But what idea does he form of the nature of this ring? The most natural that can be; that it is formed by an opening in the centre of a septum thrown across the cavity of a gut, which he supposes to be always in a dilated and open state." Now this description does not correspond with the case under my care, for upon passing the finger about two inches up the rectum, its further passage is obstructed by a distinct hard ring, the opening through which was so small, as not to admit the passing of a middlingsize glyster-pipe without the greatest diff. culty, and if any force were employed, it gave rise to severe pain. Can this be an opening in the centre of a septum thrown across the cavity of a gut?

A gentleman, thirty-seven years of age, about cighteen months ago, began to complain of pain in the rectum upon passing his motions, continuing for a short time

* It is but justice to adk, that shortiy after the appearance of my cases, several fuitless applications for " the salt" "were made to Messrs. Joyce, Garden, squire, and other operative chemists. 
after each evacuation. The bowels were acted upon from three to six times in the twenty-four hours; the motions were loose, and occasionally tingod with blood; a continual oozing from the anus of bloody mucus; yet the seneral health good. About nine months back the pain in passing the motions became very acutc; the bowels were acted on from six to eight times-a day, the feces passing with diffculty, and a continual bloody purulent discharge came from the anus; the general health became very much impaired. Mr. Salmon's opinion upon the case was requested, and he, after a careful examination, pronounced it to be circular stricture of the rectum within reach of the finger, with ulceration of the mucous membrane immediately above the contraction. My patient was called into the country, which prevented his following the plan of treatment adrised, and the disease continued to make a gradual but destructive progress. In Novenuber last he was unable to leave his bed, the bowels being acted upon from twenty to thirty times a day; he also felt a constant inclination to evacuate them, and the discharge of matter from the anus increased; the situation of my patient at this time was most deplorable. A very distinguished surgeon now saw the case, whose opinion was, that there was a distinct hardened ring about two inches from the anus, not admitting the end of the firger. This gentleman was not decided as to the stricture being of a scirrhous nature, but he yet thought it a hopeless case.

Soon afterwards Mr. Salmon, having accidentally heard that my patient was in a hopeless condition, with a zeal highly creditable, expressed a desire to examine the rectum again, as he was satisfied there was simple circular stricture of the rectum within reach of the finger, and suggested a plan of treatment, consisting of alteratives, narcotics to the rectum, and dilatation of the stricture. The result has been most satisfactory; the health is improving, the bowels are not acted upon more than four or five times a day, the stricture having become so far dilatable as to admit $m y$ passing the rectum plug No. 5, without much pain or difficulty, though to do this eight weeks back wonld have been impossible, for the aperture would barely admit the plug No. 1 ; added to which, the pain in attempting it was acute in the extreme. By inserting these simple facts you will do an act of justice to the profession, and oblige your constant reader,

SAMUrel Bacon. 41, Frederick Place, Hampstead Road, Feb. 10th, 1834.

\section{MODITICATION OF THE LITHOTRIPTIC} PRRCUTEUR.

\section{To the Editor of ThE LANCET.}

Sir,-In a late number of the London. Medical and Surgical Journal I observed a notice of an operation for breaking stone in the urinary bladder by the aid of an instrument similar to that used by Baron Heurteloup, differing in this respect only, that the moveable blade, instead of being struck down with a hammer, is forced against the stone by means of a screw. This modification of Heurteloup's percuteur seems to be approved of by Mr. Brodie and other surgeons who saw it used.

The fixing of the percuteur on the rectangular bed, without which this instrument can be of little service, the sound of the hammer, and the expense of the rectangular bed itself, are great disadvantages in the operation as practised by Heurteloup; and any modification of the apparatus which will render the operation more simple in its nature must be considered a valuable addition to our means of treating urinary calculi.

About two months ago I put into the hands of Mr. M Leod, our celebrated cutler a model of an instrument, which, when completed, I fancied might possess this character. Mr. M'Leod had the instrument made in his usual excellent style, and the trials which have been made on the dead and living subject have fulfilled the anticipations I had formed of its utility and power. The instrument is similar in most respects to the percuteur. A rack is cut on the lower surface of the sliding blade, at the end next the operator's hand, and a pernion which is placed underneath it. Both are contained in a box ahout three inches long and one square, and the wheel is moved by a handle, projecting from the right side of the box, which, according to the force required, may be of any length the operator chooses. Since this instrument was made I have seen one constructed by Charriere of Paris, in which the moveable blade is forced against the stone by means of an ircn screw, and this I suppose is of the same nature as the one lately used in London. The modification I have described, however, seems to me to be more simple and more easily managed. Both are calculated to supersede the necessity of the rectangular bed, and do away with other objections to the lichontritic process which $\mathrm{I}$ have already alluded to.

I beg that you will insert the following letter from Mr. Liston, which, coming 